\title{
El ángel exterminador de Luis Buñuel: Auto sacramental cinematográfico*
}

\begin{abstract}
*Una versión anterior de este ensayo apareció en CineLit: Essays on Peninsular Film and Fiction recopilados por Jaume Marti Olivella, George Cabello Castellet y Guy H. Wood. Portland OR: Portland State y Oregon State Universities, 1992: 31-39. El presente ensayo ha sido corregido y aumentado.
\end{abstract}

NANCY J. Membrez

University of Texas at San Antonio 


\section{Resumo}

"Todavía soy ateo, gracias a Dios" ha declarado el director español Luis Buñuel, y sin embargo, ha creado en El ángel exterminador un auto sacramental para nuestros tiempos, más cercana a la tradición hispano-católica literaria que a las obras francesas existencialistas con las que esta película suele compararse. En este ensayo intento aclarar los motivos bíblicos y literarios que informan la estructura, el desarrollo y el desenlace de esta obra maestra del cine y ofrecer una interpretación. De gran importancia son episodios del Génesis, del Apocalipsis y El gran teatro del mundo, auto sacramental de Calderón de la Barca.

\section{Palabras clave}

Buñuel, tradición hispánica, motivos bíblicos y literarios.

\section{Abstract:}

El Angel exterminador is an "auto sacramental" for our time and it is more close to the theatrical Spanish tradition than to the French existentialist works to which many critics use to compare the Buñuel's films. This essay is an attempt to explore some aspects of biblical and literary motifs which interfere on the structure of film. One can observe important episodes related to de Genesis, to the Apocalypses and to Calderón de la Barca "auto sacramental" El gran teatro del mundo.

\section{Keywords}

Buñuel, Spanish tradition, biblical and literary motives. 
Bis repetita placent. ${ }^{1}$

- Horacio.

$667 \begin{aligned} & \text { odavía soy ateo, gracias a Dios" }{ }^{2} \text { ha declarado el director } \\ & \text { español Luis Buñuel, y sin embargo, ha creado en } E l \\ & \text { ángel exterminador un auto sacramental para nuestros }\end{aligned}$ tiempos, más cercano a la tradición hispano-católica literaria que de las obras francesas existencialistas y surrealistas con las que esta película suele compararse. Hasta la fecha se han dado casos de errores imperdonables al tratar las películas de Buñuel rodadas en español. ${ }^{3}$ Por ejemplo, en su estudio semiótico Paul Sandro se equivoca lamentablemente al analizar la frase "Nuestras vidas son los ríos que van a dar en la mar, que es el morir". Estas metáforas Sandro las encuentra muy raras (77), pero cualquier hispanohablante culto reconocería las famosas "Coplas por la muerte de su padre" de Jorge Manrique. Está claro que Sandro, profesor de francés, no las reconoció. Para colmo, el guión de esta película publicado por la Editorial Aymá de Barcelona en 1964 es una pésima traducción del francés con lagunas y errores que apenas refleja la película en su forma realizada.

1. V.g. "Las cosas repetidas dan placer".

2. Entrevista que data de 1960 con Manceaux (120) y Mi último suspiro (170). También comenta: "Fórmula que sólo en apariencia es contradictoria"

3. Edwards corrobora este comentario (275-276): "To be familiar with the Freudian and surrealist aspects of Buñuel's work and ignorant of his debt to his Spanish background is to do the man and his art less than justice. It is, in effect, Buñuel's Spanishness which colours his work so strongly and which so many critics, lacking a real knowledge of Spanish culture and attitudes, fail to grasp". 
Habiendo leído y discrepado con mucha crítica escrita acerca de esta película, en este ensayo quisiera yo aclarar los motivos bíblicos y las fuentes literarias españolas que informan la estructura, el desarrollo y el desenlace de esta obra maestra del cine.

El auto sacramental se remonta a los tiempos más remotos de la literatura española y tiene su origen en los milagros y autos que se suponen representados en la Iglesia católica del medievo. Luego éstos fueron rechazados por la Iglesia al introducirse elementos profanos y burlescos en la representación. Durante el barroco Pedro Calderón de la Barca consiguió cuajar el auto sacramental en la forma en que todavía se conoce, v.g. El gran teatro del mundo (¿1633?). Una obra alegórica, relativa a la religión, encarnación de conceptos abstractos, el auto sacramental consta de tres elementos importantes: la teología católica, una alegoría y una apoteosis final (García López 333-335; Pequeño Larousse), elementos que se manifiestan plenamente en la película El ángel exterminador rodada por Buñuel en México en 1962.

En lugar de los personajes alegóricos tradicionales (e.g. La riqueza, La pobreza, La hermosura, etc.) se ofrece todo un panorama burgués, más apropiado a nuestra época. Este es un "gran teatro del mundo" poblado de nuevos arquetipos que han surgido de la burguesía triunfante, egoísta, satisfecha y pretenciosa, el blanco favorito de los dardos de Buñuel. Entre los veintiún personajes encerrados hay un arquitecto, un médico, una cantante de ópera, un coronel, un director de orquesta, un diplomático, un hombre de negocios extranjero y una manada de esposas ociosas. Todos manifiestan o aspiran a manifestar el consumo ostentoso: los caballeros llevan el frac de rigor y las damas lucen peinado de moda idéntico y vestido talar. Todos son católicos (se habla de ofrecer novenas, hacer un peregrinaje a Lourdes) aunque hay dos masones y una bruja ocultos entre ellos. Estos ricos ya desnaturalizados y deshumanizados, productos de una sociedad corrupta, enajenados el uno del otro y enajenados de sus propios cuerpos, no caen en la cuenta de su dilema hasta demasiado tarde. En cambio, siendo criaturas más ligadas a la naturaleza y al instinto animal los criados y los cocineros "olfatean" el peligro y huyen de la casa en el instante en que llegan los elegantes invitados. Por el 
momento estos representantes de la clase trabajadora están a salvo, todos menos Julio, el mayordomo. Por otra parte, el abate lujurioso e hipócrita y el cura gordo no son atrapados la primera vez, pero del segundo encuentro con el Angel exterminador no saldrán absueltos.

Desde las primeras escenas interviene lo divino. La película arranca de un plano de una iglesia seguido por el de un rótulo: la calle de la Providencia, número 1109. Si estos personajes fuesen pastores de la época bíblica no nos extrañarían nada los sucesos sobrenaturales subsiguientes. Desplazada la acción al contexto moderno la historia nos parece misteriosa, maravillosa e inexplicable. Hoy día nos choca mucho la idea de que Dios intervenga en nuestros asuntos de una manera tan directa. Sin embargo, nada más lógico dadas las peripecias 5 de nuestros antepasados que se relatan en la Santa Biblia. Los deslices, desplazamientos, sueños y repeticiones que observamos en la película evidencian la ruptura del tiempo y anuncian el próximo cataclismo.

Los números 3 y 7 , números místicos, hacen un papel importante en la obra. De hecho el número de aislados es veintiuno, cuyos únicos factores son tres y siete. $\mathrm{El}$ número tres representa a la Santísima Trinidad y cuando el reloj da las tres de la madrugada otro "día" de aislamiento se marca. "Es la hora más deliciosa e íntima de la noche" según el anfitrión Nobilé, quien se arrepentirá de haber invitado a sus amigos a cenar después de la ópera. El tiempo se distorsiona: o pasan horas enteras en pocos minutos o el tiempo se alarga (guión). Además, viendo la película imagen por imagen se nos revela que ese reloj antiguo tiene un dibujo de un barco velero, detalle que recuerda el título original de esta película "Los náufragos de la calle de la Providencia". No es una mera coincidencia de que lleven seis días encerrados y entonces vayan a misa el séptimo día para dar gracias. El número siete nos recuerda que, según el Génesis, Dios

4. Edwards corrobora este comentario (275-276): "To be familiar with the Freudian and surrealist aspects of Buñuel's work and ignorant of his debt to his Spanish background is to do the man and his art less than justice. It is, in effect, Buñuel's Spanishness which colours his work so strongly and which so many critics, lacking a real knowledge of Spanish culture and attitudes, fail to grasp".

Significação $29 \cdot 31$ 
creó el mundo en seis días y descansó el séptimo día. Lo que no se indica es lo que pasará al día siguiente. De acuerdo con las creencias de ciertas culturas habrá un cataclismo mediante el cual Dios descartará lo existente y comenzará de cero. En el tiempo onírico aborigen se pronostican los sucesos venideros; para los cristianos el fin y el nuevo recomenzar se anuncian en el Apocalipsis de San Juan Apóstol. Efectivamente, en la película apenas concluye el primer encierro cuando arranca otro. En la escena final (plano general de la iglesia y las ovejas) aparece la palabra "Fin", un comentario irónico que destaca el fin de la película, pero no el de la plaga/ juicio final que se ensancha para tal vez desembocar en el fin del mundo.

Personaje bíblico por excelencia y portavoz del Todopoderoso el Angel exterminador hace un papel clave en el Antiguo Testamento y volverá a participar en el Juicio final según el Apocalipsis. ${ }^{5} \mathrm{Su}$ actuación en el Génesis es ejemplar. Cuando Dios castiga a Adán y Eva expulsándoles del Paraíso deja un ángel centinela a la puerta del mismo para que éstos no vuelvan a entrar (Génesis 2-3). Luego, Dios manda que el Angel exterminador castigue a los habitantes de Sodoma y Gomorra, ciudades espléndidas de la antigüedad entregadas al vicio y al pecado. Sólo se salva Lot, quien ruega la clemencia del Señor pidiéndole que halle siquiera un hombre honrado entre los enviciados para evitar la destrucción de las ciudades. Lot, no obstante, vacila ante los avisos divinos y tarda mucho en marcharse con su mujer (Génesis 19). En el libro del Exodo (11-12) Moisés pide al faraón que libere a los hebreos dándoles permiso para abandonar Egipto y marcharse a la Tierra prometida. Al serle negada tal petición, Moisés anuncia la llegada del Angel exterminador, que matará al primogénito de cada familia si no se ha marcado la puerta con la sangre de un cordero sacrificado. Esta última "plaga" (así se llama en la Biblia) precipita la fuga de los hebreos, la inundación del Mar Rojo y la promulgación de los Diez mandamientos.

5. Esteve (244) apunta más intervenciones biblicas del Angel exterminador: Samuel II, 24, versos 16ff; Reyes II, 19, verso 35; Exodo 12, verso 23; Salmo 78, verso 49. 
No es una mera casualidad de que las intervenciones divinas del Génesis se asemejen a muchos sucesos de la película. En El ángel exterminador, el personaje principal que rotula la película es invisible pero omnipresente. De hecho, su imagen se ve pintada en uno de los armarios del salón y aparece a menudo como trasfondo/ coro griego de las conversaciones de los personajes. ${ }^{6}$ Los planos de tres cuartos, es decir de cabeza a rodillas, ${ }^{7}$ y los planos medios (pies a cabeza) permiten que la cámara (el mismo Ángel) espíe al grupo, buscando en vano, como en la Biblia, a una persona honrada en la Sodoma y Gomorra del siglo XX, la ciudad moderna. Además, la vacilación de Lot se repetirá en la abulia de los encerrados de la Calle de la Providencia. ${ }^{8}$ También se evidencia la necesidad de un sacrificio para que éstos vuelvan a su Paraíso terrenal. En este sentido las imágenes confundidas de Nobilé y el cordero por sacrificar no son nada gratuitas.

¿Por qué se habrá condenado a estos individuos en particular? ¿Cuáles serán sus pecados? Pues, Edmundo Nobilé, el anfitrión linajudo y cornudo, que se mete a redentor (un cruce de cordero rumiante por sacrificar y crío del carnero con cuernos) y casi le crucifican, ${ }^{9}$ guarda opio en un cofre con el que divertía a sus amigos en otras ocasiones. El portal blasonado de su palacio nos recuerda el abolengo "noble" de los Nobilé (que suena a "noble" de por sî) y evoca otros umbrales: el del Cielo y el del Infierno. Es más. Nobilé no es un apellido ni inventado ni escogido al azar por Buñuel. Éste o su colaborador habrá recordado que el general Nobile (sin acento), aquel jefe italiano del dirigible Italia, protagonizara un episodio escandaloso y vergonzoso en la historia del mundo. Bien sabido es que desde los tiempos más remotos la honra marítima exige que el capitán perezca al hundirse la nave o, como mínimo, que sea el último en salvarse. No obstante la fuerza de esta tradición, al desplomarse el Italia en una expedición al Polo norte en 1928, el general Nobile

\footnotetext{
6. El guión confirma la identidad de la imagen.

7. Ver Durgnat 15.

8. Lo que Higgenbotham llama el conformismo del grupo (153).

9. Dice el refrán popular: "Al que se mete a redentor, lo crucifican".
} 
( in acento), jefe de expedición que lucía la camisa negra de los fascistas italianos, se salvó el pellejo primero y dejó perecer a veinte compañeros y tripulantes. ${ }^{10}$ Por lo tanto, su tocayo buñueliano y repetición grotesca Edmundo Nobilé, como "capitán” de los "náufragos de la calle de la Providencia", tendrá su propia prueba de fuego para expiarse del pecado. Incluso, los dos hombres coinciden en ostentar bigotes y barba, siendo el mexicano el más joven de los dos.

Los otros encerrados no serán menos. El coronel Alvaro Aranda y Lucía Nobilé la anfitriona son amantes adúlteros. El director de orquesta Alberto Roc, masón, casado con la joven Alicia, es un viejo verde, víctima de excesos sexuales que le llevan a intentar violar a las mujeres mientras éstas duermen. Los hermanos Juana y Francisco Avila tienen una relación incestuosa. Leonora, que se muere de cáncer, propone un peregrinaje a Lourdes, pero en seguida este pensamiento se vuelve grotesco al anunciar ella su deseo de comprarse "una virgen lavable de caucho", una perversión del verdadero espíritu religioso. Raúl se muestra iracundo y cruel al tirar las píldoras fuera del alcance de Cristián. A pesar de su nombre Cristián Gálvez no es nada cristiano, sino masón y cornudo. Rita, la mujer de Cristián, es adúltera con el abate Sampson, tutor y tal vez padre de sus cuatro hijos. El doctor se condena por demasiado racional, por no aceptar la posibilidad de lo milagroso; ${ }^{11}$ Leandro

10. He aquí el texto relevante del reportaje "Panorama mundial" de Nuevo Mundo [23]: "Ya se conoce el trágico balance de la expedición hacia el Polo del dirigible Italia. Catorce muertos, seis desaparecidos, cuatro agonizantes y dos heridos graves. Unicamente el general Nobile, jefe de la expedición, se encuentra a salvo y sin inmediato peligro para su salud.

Los dramáticos episodios del cautiverio entre el hielo conmueven al mundo. Es un poema trágico. La tragedia constante de la ciencia en su lucha contra la naturaleza. La aventura del Italia tiene una grandeza épica llena de horror. Poema moderno que, a pesar de su promesa, no se atreverá a escribir [Gabriel] D'Annunzio. Porque en él falta el héroe. O mejor, el heroísmo del protagonista. El general Nobile, poniéndose en salvo el primero mientras sus compañeros y subordinados perecían, no es precisamente el héroe apropiado para el ígneo verbo d'annunziano, a pesar de las obligaciones que contrajo al vestirse sobre la blanca clámide clásica, la negra camisa del fascio...".

11. Buñuel (171): "[La ciencia] me parece presuntuosa, analítica y superficial. Ignora el sueño, el azar, la risa, el sentimiento y la contradicción, cosas que me son preciosas". 
Gómez, por antisemita y por vivir en los Estados Unidos. Ana Maynar practica la brujería puesto que las patas de gallo ("las llaves") aparecen en su bolsa. Beatriz y Eduardo mantienen relaciones sexuales prematrimoniales y caen en el pecado mortal del suicidio durante el encierro. Leticia la Walkiria se muestra voluntariosa al hacer añicos una ventana con un cenicero (aunque su presunta virginidad, "ese oscuro objeto del deseo", le permite dar con la solución).

Según el delirio de Ana la mano desmembrada e inerte del señor Russell cobra vida y la ataca. En realidad, ésta es una repetición de una escena de The Beast with Five Fingers, película a la que contribuyó Buñuel en 1945 en Hollywood (Buñuel 184). Además de mostrar la preocupación surrealista por las manos cortadas, nos hace pensar en dos obras españolas anteriores al siglo XX: el "Romance de la mano muerta", recogido por Gustavo Adolfo Bécquer y especialmente El sueño de las calaveras (publicado en 1627), sátira del escritor barroco Francisco de Quevedo en la que al sonar la trompeta del Apocalipsis los ladrones recién despertados rechazan la reintegración de sus manos pecadoras. En la pesadilla de Ana, con el cataclismo ya cerca y el tiempo desplazado, la mano de Russell ha resucitado y anda por el mundo. ¿Qué tipo de hombre habrá sido Russell entonces? ¿Lascivo, asesino, ladrón? Sólo nos enteramos de que no aguanta las bromas y no domina el castellano del todo.

¿Y Julio, el mayordomo? Nos preguntamos por qué se habrá atrapado este personaje de clase baja. Sencillamente, por presumido. Es el único que se mueve entre dos mundos, entre el salón principal (espacio de la burguesía) y la cocina (espacio de la clase trabajadora), pero tras sentenciar "Cada vez el servicio se vuelve más impertinente" se muestra ambicioso y acaba encerrado con sus amos. Además, no hemos de olvidar que al encerrarse este personaje, los aislados suman el número mágico de veintiuno. En otra escena importante para este personaje educado por los jesuitas (como el mismo Buñuel), Julio ofrece una fuente de bolitas de papel a la señorita Beatriz de modo que recrea la imagen de un cura que ofrece una hostia sacrílega a una comulgante. Este sacramento, cuya presencia define el auto sacramental, no puede faltar, desde luego.

Y así sucesivamente. Todos han contrariado los Diez mandamientos o los contrariarán estando aislados. Según la vieja 
tradición aristocrática "la nobleza obliga", pero aquí la burguesía obliga y da mal ejemplo a la clase trabajadora. La flor y nata de la sociedad latina fracasa solemnemente en este micro-juicio. ¿Habrán asistido a misa antes de su encierro inesperado? Cabe pensar que no. Su dilema se expresa bien en el dicho popular "que Dios nos coja confesados". Bajo su fachada tan respetable y lujosa ya han caído a escondidas en la crueldad, la violencia y la suciedad que tanto aborrecen (palabras de Nobilé). Sólo hace falta interrumpir la cadena de alimentación y poder que posibilita su superioridad social para revelar en seguida lo que son en realidad. Después de su escape hay un efímero momento de alivio, así como en la tragedia clásica griega, en el que se creen a salvo antes de verse atrapados otra vez. Al asistir los penitentes a la misa subvencionada por los Nobile, ¿se habrán arrepentido de declarar que la clase baja es insensible al dolor? ${ }^{12}$ Queda manifiesto que han vuelto a sus ritos, privilegios, prejuicios y pecados.

Hay una perspectiva que se destaca a lo largo de la película que nos recuerda la idea de El gran teatro del mundo: un plano general del salón grande desde el saloncito, a veces con la presencia del mayordomo en primer término (Fig. 1).

12. La escena en que se pronuncian estas palabras reproduce textualmente un incidente con Salvador Dalí. (Buñuel 181) 


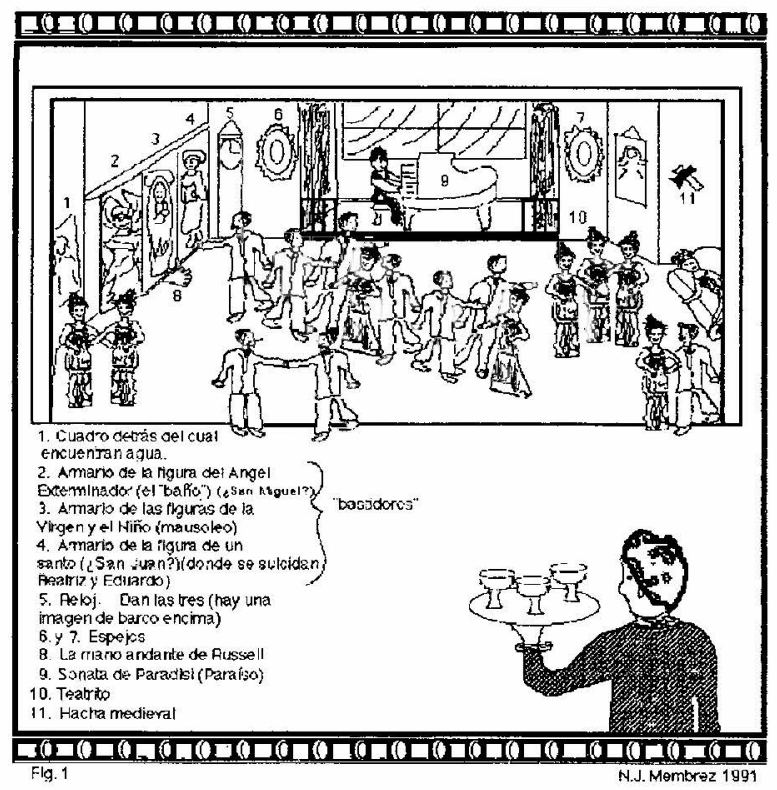

En este plano los espacios teatrales definidos por los umbrales se observan claramente: nuestro espacio, el del saloncito (v.g. el de la película), el del salón grande y el de un teatrito con piano y telón. Julio el mayordomo observa a los invitados desde esa perspectiva lejana: los invitados parecen moverse como actores en escena, peces en un acuario, fieras enjauladas, o pasajeros que se pasean por la cubierta de esta "nave de locos" moderna. Los bastidores de este teatro improvisado son los armarios que se observan a la izquierda del salón pintados con las imágenes del Angel exterminador, la Virgen y el Niño, y la de un santo (tal vez San Juan), los cuales se convierten en retrete, mausoleo y nido de amor y muerte. La película puntualiza que la única salida de los armarios será la muerte. Más tarde, el plano general del salón nos muestra una cueva en la cual los encerrados, reducidos a trogloditas, se ponen en cuclillas alrededor de una hoguera en pleno salón para asar los corderos que han matado con sus propias manos. Al llegar al clímax en que la Walkiria les hace repetir los primeros momentos de su encierro y consigue romper la 
barrera invisible, ${ }^{13}$ nos asombra la fuga precipitada de los invitados al escaparse de su "escenario", ya que en el teatro esperamos que se mantengan las distancias gracias al proscenio ( $\mathrm{y}$ en el cine gracias a la pantalla). Ese muro invisible volverá a romperse sucesivamente al abalanzarse todos hacia nosotros indicando que este "gran teatro del mundo" puesto en tela de juicio también nos alcanzará a nosotros. (Fig. 2) ${ }^{14}$

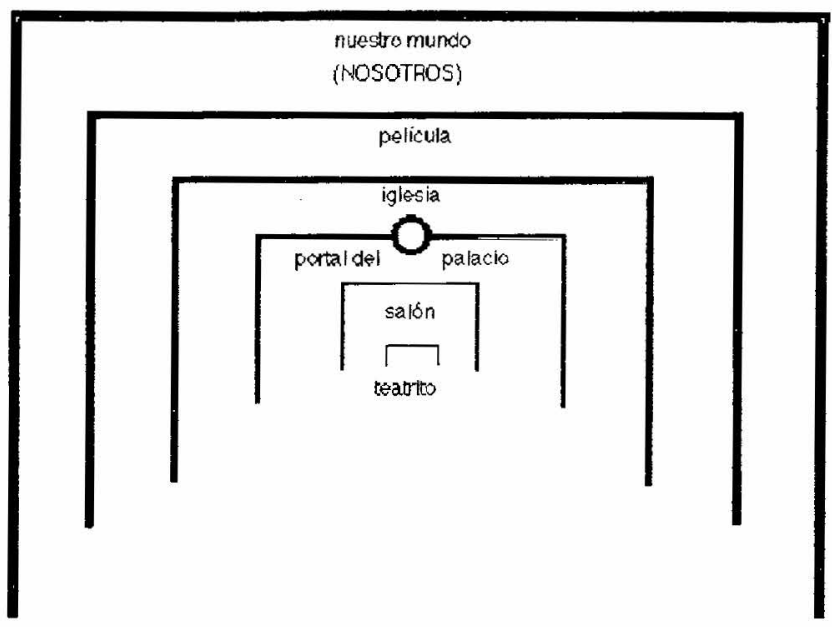

Fig. 2

Según Buñuel la vida es repetitiva y él se nos confiesa en su autobiografía que le fascinan las repeticiones (231), tal vez porque Carlos Marx declaraba que al repetirse la historia, la primera vez se

13. Varios personajes - Russell, Julio, Lucía, la multitud que les espera, y el curase detienen en el umbral, miran hacia arriba, se desconciertan y retroceden.

14. Recuerdo nítidamente la primera vez que vi El Angel exterminador. Corrian los años 70 y mi marido y yo salimos a verla a pesar del temporal que azotaba la ciudad de Santa Bárbara (de California) aquella noche. Al terminar la película el público se apiñaba en el umbral del cine vacilando entre quedarse y marcharse mientras llovía a cántaros, tronaba y relampagueaba. Nos reiamos nerviosísimos por el parecido de nuestra situación con la de la película. Varios anunciaron, solemnes, que más valiera que nos fuéramos corriendo con paraguas o sin él. Y así fue. Nos empapamos camino del parking, ipero valió la pena! 
trata de una tragedia y la segunda vez, una farsa (1). Otros han mencionado las escenas dobles, pero ningún crítico ha notado, que yo sepa, que éstas no sean perfectas. En el plano general de la entrada de los invitados se producen ligeras variantes al llegar éstos la segunda vez: la perspectiva de la cámara y el diálogo varían. Desde este momento clave se nos avisa que el tiempo se está desgarrando. Luego, el anfitrión ofrece un brindis por Silvia, la soprano que acaba de cantar la ópera de G. Donizetti Lucía de Lamermoor (cuya aria principal del tercer acto se llama "de la locura," nada menos). La primera vez que Nobilé se levanta, los invitados le hacen caso; la segunda vez, ni le prestan atención. Comentando otra repetición el mismo Buñuel documenta las tres veces (con variantes) que se presentan Cristián y Raúl el uno al otro. Aun cuando los encerrados dan con la clave la repetición no puede ser perfecta porque ya han muerto tres de los personajes que escuchaban la sonata de Paradisi ("paraíso" en italiano, una referencia nada frívola): Russell, Beatriz y Eduardo. Hay aún más ejemplos de gestos y parlamentos repetidos a lo largo de la película. $^{15}$

Por más que haya pregonado su ateísmo, Buñuel se vale de todos los símbolos del catolicismo y del anticlericalismo peninsular. Los objetos de la cultura católica latina pueblan la película: la iglesia, el rótulo de la calle y los cuadros antiguos de santos del salón. El léxico de los personajes también refleja este catolicismo patente: la novena; el te deum, consumatum est y otros términos en latín. Al conseguir abrir una cañería en la pared para encontrar agua los encerrados recrean la escena bíblica del Antiguo testamento (retratada

15. Edwards analiza las repeticiones (175-180); Schillaci (205); Juan Luis Buñuel las explica también en Mellen (254-256). Origen de algunas escenas: el bandazo (Aranda 209); escena del espejo (Buñuel 55); alucinaciones en el "baño" (J.L. Buñuel en Mellen 254-246).

Hay una repetición incluso de otra película mexicana, a saber: las palabras y tono de "No me abandones. No me dejes sola" (en boca de varios personajes) parece ser una repetición burlesca de una escena melodrámática y archiconocida de la película clásica Maria Candelaria (1943) protagonizada por Dolores del Río. 
en un famoso grabado de Gustavo Doré) en la cual los hebreos beben del manantial que brota de una piedra. Volviendo al Evangelio, la gran cena después de la ópera parodia la última cena del Señor y los pedazos de papel en la fuente de plata son una parodia de la hostia. Las ovejas y un oso ${ }^{16}$ andan sueltos por la casa, en primer plano como un gag de la anfitriona (según Buñuel) y en segundo, como cumplimiento de la profecía del Apocalipsis de que las fieras vivirán juntos. Según Mi último suspiro, Buñuel iba a volar a los invitados para concluir la película, así como acertó a desenlazar Ese oscuro objeto del deseo (1977), pero cambió de idea (Aranda 209). El fin que sí eligió hace eco del Don Juan Tenorio, drama clásico español de José Zorrilla (1844), cuyo papel principal Buñuel representó en los años treinta (Edwards 14-15). En el desenlace de esa obra la virgen Doña Inés es responsable por la salvación de Don Juan, su raptor. En El ángel exterminador, Leonora, la que se queda calva, nos profetiza: "Sólo la Virgen nos puede sacar de aquî'. Efectivamente, la presunta "virgen" da con la clave, pero no es la Virgen María sino un simulacro de ella, otra repetición burlona. Leticia la Walkiria llamada así por fiera y virgen es la única doncella que queda entre las señoras pecadoras del salón, según ellas mismas. El crítico Raymond Durgnat ha escrito que Nobilé deflora a la Walkiria durante la última noche del encierro (129), pero el guión no respalda esta interpretación. Leticia ayuda a Nobilé a velar antes de su "sacrificio humano" (v.g. suicidio), reproduciendo visualmente el cuadro plástico de la Piedad: la Dolorosa y su Hijo. Luego, cuando se corre el telón (para revelar en seguida un irónico deus ex machina), la Walkiria sí tiene el pelo desarreglado, pero el efecto es más bien ambiguo.

Se observa una simetría perfecta en esta obra. El ciclo está completo. La película arranca de un plano general de la iglesia, cuna del teatro, en que se oye un Te deum, y ahí concluye. Tras los gritos

16. Además, yo lo tomo por un gag visual: "hacer el oso" es portarse mal en sociedad. Lo considero un reflejo del comportamiento de los llamados "caballeros" atrapados en el salón. 
de la multitud un rebaño de ovejas ${ }^{17}$ se acerca a los nuevos damnificados, para los cuales el círculo se ha ensanchado y cerrado. Los de fuera izan la bandera amarilla de cuarentena, ${ }^{18}$ pero no comprenden que no se trata de una plaga biológica. El nuevo juicio (y otro y otro...) se llevará a cabo para que el Angel exterminador, brazo derecho de un Dios colérico, caprichoso y quizá bromista, siga buscando la razón de no arrasar a la humanidad.

Ahora bien. Si acaso Ud., amable lector/a, rechaza mi análisis, le ofrezco otro más breve. Si Dios no existe, está muerto o nos está indiferente, ¿entonces cómo se explica esta película? Pues cabe imaginar a un San Luis Buñuel todopoderoso que haga las veces de Dios y Angel exterminador. Teólogo y ateólogo de la Biblia, ${ }^{19}$ de los dogmas católicos y las herejías (prueba indiscutible es su película $\mathrm{La}$ vía láctea) es el mismo Buñuel -que en paz descanse-, que ha condenado a sus personajes a sufrir el encierro, a fin de que se cumpla su promesa de "poner de manifiesto con un ojo blanco y frío todo cuánto han hecho en la tierra en nombre de Dios" (citado por Schillaci 111). Teología católica, alegoría, sagrado sacramento y apoteosis final. Nada falta. Así como el párroco ateo de la novela de Unamuno, el cual nos enseña a ser buenos cristianos y a quien la Iglesia llega a canonizar solemnemente San Manuel Bueno, mártir, Buñuel nos brinda el mejor auto sacramental desde El gran teatro del mundo.

¡Que Dios nos coja confesados!

17. En 1930 Ignacio Carral publicó en un reportaje de Estampa-una revista gráfica de alta calidad de Madrid-que había un pueblo abandonado a pocos kilómetros de Madrid en el que las ovejas deambulaban y rumiaban por las casas y por la iglesia [10-12]. Más allá del uso simbólico del "cordero de Dios", de la parábola bíblica de la "oveja perdida", de la metáfora manoseada de la masa ignorante e, incluso, más allá de la larga historia de la oveja para el desarrollo económico de Castilla, resulta sugestivo pensar que Buñuel se acordara de este reportaje e incorporara las ovejas literalmente a dos escenas de la película: cuando las ovejas aparecen inexplicablemente y pasan al salón en donde los damnificados las matan y las consumen y más tarde cuando un rebaño de ovejas se acerca a la iglesia en donde están atrapados los nuevos encerrados. A pesar del "fin" de la película parece cierto que va a entrar en ella, repitiendo en escala mayor la escena ovejuna descrita por Carral.

18. La palabra "cuarentena" también es sinónimo de "cuaresma".

19. Las frases bíblicas salpican Mi último suspiro. 


\section{Bibliografia}

ARANDA, Francisco. 1975. Luis Buñuel: A Critical Biography. Trad. de David Robinson. Londres: Secher and Warburg. (Ed. original: Barcelona: Lumen, 1969).

BÉCQUER, Gustavo Adolfo. 1987. Leyendas. $2^{\mathrm{a}}$ ed. de Pascual Izquierdo. Madrid: Ediciones Cátedra.

BRADBURY, Ray. 1998. Something Wicked This Way Comes. Nueva York: HarperCollins, 1998.

BUÑUEL, Juan Luis. 1978. "A letter on The Exterminating Angel." (16 agosto 1963). Originalmente publicado en Film Culture 41 (Summer 1966). Reimpreso en The World of Luis Buñuel: Essays in Criticism. Ed. de Joan Mellen. Nueva York: Oxford University Press,

BUÑUEL, Luis. 1964. El ángel exterminador. Trad. de Manuel Villegas López. Barcelona: Editorial Aymá.

1982. Mi último suspiro (Memorias). Trad. de Ana María de la Fuente. Barcelona: Plaza y Janés, Eds.,

CALDERÓN de la BARCA, Pedro. 1931. El gran teatro del mundo. Madrid: Editorial Plutarco.

CARRAL, Ignacio. 1930. "Un pueblo abandonado por sus habitantes, a pocos kilómetros de Madrid”. Estampa 3.112 (4 marzo 1930): [10-12].

DURGNAT, Raymond. 1977. Luis Buñuel. Berkeley: University of California Press.

EDWARDS, Gwynne. 1982. The Discreet Art of Luis Buñuel: A Reading of his Films. Boston: Marion Boyars.

ESTÈVE, Michel. 1963. "The Exterminating Angel: No Exit from the Human Condition." Etudes cinematographiques 22-3 (Printemps de 1963). Traducido y reimpreso en The World of Luis Buñuel: Essays in Criticism. Ed. de Joan Mellen. Nueva York: Oxford University Press, 1978.

GARCÍA LÓPEZ, José. 1969. Historia de la literatura española. $14^{\mathrm{a}}$ ed. Madrid: Editorial Vicens-Vives.

HIGGENBOTHAM, Virginia. 1979. Luis Buñuel. Boston: Twayne.

Significação $29 \cdot 42$ 
KYROU, Ado. 1963. Luis Buñuel: An Introduction. Trad. de Adrienne Foulke. Nueva York: Simon and Schuster.

MANCEAUX, Michele. 1960. "Entrevista con Luis Buñuel". L'Express, 12-5-1960. Reimpreso en Kyrou.

MARX, Karl. 1963. The Eighteenth Brumaire of Louis Napoleon [El dieciocho brumario de Luis Napoleón]. Nueva York: International Publishers.

"Panorama mundial". Nuevo Mundo 35.1800 (20 julio 1928): [23]. + Foto.

QUEVEDO, Francisco de. 1917. Los sueños. Ed. de Julio Cejador y Frauca. Madrid: Ediciones de La Lectura.

SAGRADA BIBLIA. 1968. $27^{a}$ ed. de Eloíno Nácar Fuster y Alberto Colunga. Madrid: Biblioteca de Autores Cristianos.

SANDRO, Paul. 1987. Diversions of Pleasure: Luis Buñuel and the Crisis of Desire. Columbus, OH: Ohio State University Press.

SCHILLACI, Peter P. 1973. "Luis Buñuel and the Death of God". En Three European Directors. Ed. de James M. Wall. Grand Rapids, MI: William B. Erdmans Publishing Co.

UNAMUNO, Miguel de. 1968. San Manuel Bueno, mártir. $2^{\mathrm{a}}$ ed. Madrid: Alianza Editorial, 1968.

ZORRILLA, José. 1970. Don Juan Tenorio (1844). Madrid: EspasaCalpe, 1970. 